International Journal of Osteoarchaeology

Int. J. Osteoarchaeol. (2011)

Published online in Wiley Online Library

(wileyonlinelibrary.com) DOI: 10.1002/oa.1274

SPECIAL ISSUE PAPER

\title{
Investigating Variation in the Prevalence of Weathering in Faunal Assemblages in the UK: A Multivariate Statistical Approach
}

\author{
R. MADGWICK $^{\mathbf{a} *}$ AND J. MULVILLE ${ }^{\mathbf{b}}$ \\ a School of Applied Sciences, Bournemouth University, Talbot Campus, Fern Barrow, Poole, UK \\ b School of History, Archaeology and Religion, Cardiff University, Colum Drive, Cardiff, UK
}

ABSTRACT This article presents an exploratory multivariate statistical approach to gaining a more comprehensive understanding of variation in subaerial bone weathering in a British context. Weathering is among the most common taphonomic modifications and provides a crucial line of evidence for reconstructing the taphonomic trajectories of faunal assemblages and archaeological deposits. It provides clear evidence for prolonged subaerial exposure either before deposition in a context or because of later disturbance. In combination with other taphonomic indices such as gnawing, trampling, abrasion and fracture patterns, weathering can be used to reconstruct depositional histories and to investigate the structured treatment of different body parts or taxa in deposition. However, a broad range of factors affect the prevalence and severity of weathering, and therefore patterns can rarely be interpreted at face value. Many variables such as predepositional microenvironment cannot be traced archaeologically. Other contributory factors pertaining to the structural properties of elements and taxa can be discerned and must be taken into account in interpreting weathering signatures. However, disagreement exists regarding which variables are most important in mediating weathering. In addition for zooarchaeologists to interpret modification patterns, it is necessary for elements and taxa that are most likely to be affected by weathering to be defined. This is the case as deposits that are dominated by those classes of remains are likely to exhibit greater modification than those that are not, even if depositional histories were similar. Through a combination of classification tree and ordinal regression analysis, this article identifies which archaeologically recoverable variables explain the greatest variance in weathering and which anatomical elements and taxa are most likely to be affected in archaeological deposits in the UK. Copyright @ 2011 John Wiley \& Sons, Ltd.

Key words: depositional histories; formation processes; modification; multivariate statistics; taphonomy; weathering; zooarchaeology

\section{Introduction}

Taphonomic modifications provide a wealth of information on the depositional histories of faunal assemblages and archaeological deposits. Bones represent the optimal archaeological resource for reconstructing the taphonomic trajectories of deposits. They are resistant enough to decay to survive in abundance in the archaeological record (depending on the depositional environment) but are also soft and malleable to

\footnotetext{
* Correspondence to: School of Applied Sciences, Bournemouth University, Talbot Campus, Fern Barrow, Poole, UK

e-mail: rmadgwick@bournemouth.ac.uk
}

the degree that they can be altered by a range of processes, thereby taking an imprint of their taphonomic history. The holistic analysis of taphonomic modification can inform the on-site formation processes, the integrity of a deposit and the predepositional treatment of different taxa or body parts (e.g. Serjeantson, 1991, 1996; Bar-Oz \& Munro, 2004; Enloe, 2004; Todisco \& Monchot, 2008; Madgwick, 2008, 2010; Russell, 2010).

Despite a thorough consideration of taphonomy being widely recognised as crucial to interpretation, outside Palaeolithic zooarchaeology, it remains relatively rare that comprehensive taphonomic recording is undertaken. Consequently, the potential of zooarchaeological data is 
infrequently maximised. The extra time and associated cost of collecting and analysing data may at times hamper attempts. However, the greatest stumbling block is likely to be the myriad factors hindering taphonomic analysis and subsequent interpretation. This problem centres on the diverse range of variables and biases affecting the rate and effect of different taphonomic processes, and the relative paucity of research on the subject means that a confident and meaningful interpretation of data is difficult. It is crucial to gain a more thorough understanding of the variables which mediate modification for valid interpretation to be made.

This article focuses on weathering and presents results from a multivariate statistical study on a large data set from eleven British sites. Analysis aims to determine which archaeologically or zooarchaeologically recoverable variables explain the greatest variance in weathering and which taxa and anatomical elements are most likely to be affected by the modification in faunal assemblages. Findings facilitate a more valid interpretation of weathering patterns.

\section{Weathering}

This article is concerned with subaerial weathering, which causes the distinct modification patterns from the subterranean erosion and the destruction of bone caused by chemical weathering. Subaerial weathering represents a crucial source of taphonomic information in providing evidence for prolonged subaerial exposure. It is defined as the process where the original microscopic organic and inorganic components of the bone are separated and destroyed by physical and chemical agents (Behrensmeyer, 1978, p. 153). Weathering is progressively characterised by surface cracking, flaking, exfoliation and splitting and disintegration of the bone (Steele \& Carson, 1989; Fisher, 1995: 31).

During research at the Amboseli Basin in Kenya, Behrensmeyer (1978) developed a recording strategy for weathering in medium or large mammals (Table 2, Figures 2-4). However, although weathering is a progressive linear process, reconstructing its temporal meaning is complex (Potts, 1984). Stages do not cover regular times, and experiments have shown that stages $0-2$ can pass within 2 years but stages 2 or 3 can remain on exposed bone for several years (Gifford, 1977). The complete loss of shape and skeletal integrity through weathering can occur as rapidly as 6 years or after as long as 30 (Ross \& Cunningham, 2011: 36). This wide variation results from the broad range of factors that affect the weathering rate.
Environmental conditions are critical in determining the weathering rate. Sunlight, freeze-thaw cycles, vegetation, temperature or moisture fluctuation and $\mathrm{mi}-$ crobial activity all affect weathering (Riclefs, 1973; Behrensmeyer, 1978; Millard \& Hedges, 1995: 244; Pinto Llona \& Andrews, 1999; Conard et al., 2008; Fernández-Jalvo \& Marín Monfort, 2008: 170). Weathering is far slower in tropical rainforest conditions compared with open environments (Tappen, 1994). Bone degrades faster in open habitats because of wide fluctuations in temperature and moisture (Riclefs, 1973), whereas stable environments decelerate the process (Behrensmeyer, 1978: 159; Hedges, 2002: 325). Open environments are also more conducive to weathering because of limited shelter (Ross \& Cunningham, 2011). Behrensmeyer (1978: 155) highlighted that microenvironmental conditions are more important in dictating the weathering rate than the overall character of a habitat. Therefore, patches of vegetation and multiple specimens deposited together can have a considerable effect on weathering (see Saunders, 1977). Weathering can occur in subterranean as well as subaerial contexts (Frison \& Todd, 1986; Purdy \& Clark, 1987; Lyman, 1994). There is some disagreement as to the degree to which subsurface modification occurs, although most analysts agree that it is negligible. Experiments have demonstrated that bones rapidly deposited in subterranean contexts rarely exhibit evidence of weathering (e.g. Behrensmeyer, 1978: 154; Boaz, 1982; Maat, 1993: 84), and Ross and Cunningham (2011: 126) stated that subterranean disposal effectively shuts out most weathering agents.

The structural properties of the different classes of skeletal material also have a substantial effect on the prevalence and severity of weathering. The effect of bone density on general degradation is very well attested (Henderson, 1987; Lyman \& Fox, 1989; Kreutzer, 1992; Lyman et al., 1992; Lyman, 1993; Butler \& Chatters, 1994; Elkin, 1995; Willey et al., 1997; Lam et al., 1998, 1999, 2003; Pavao \& Stahl, 1999; Behrensmmeyer et al., 2000; Dirrigl, 2001; Kooyman, 2001; Collins, et al., 2002: 386; Ioannidou, 2003: 355; Lam \& Pearson, 2005; Symmons, 2005a, 2005b, and others). As the transport of water through the bone interface has been cited as a crucial factor in causing weathering, density would be expected to have a substantial effect, as less dense bone is more porous and therefore susceptible to water transfer (Murphy et al., 1981; Hedges \& Millard, 1995: 207; Trueman et al., 2004; Smith et al., 2008). However, very little work has explicitly demonstrated the effect of the variable, and although density varies greatly at an intraelement level, the recorded patterns of weathering prevalence 
do not adhere closely to element density ranking (Lam et al., 1999; Ioannidou, 2003: 356). This suggests that weathering may not be affected by density in the same way as subsurface degradation. In any case, density is a highly problematic source of information because it varies according to a wide range of factors including taxa, element or element zone, sex, age, breed, lactation and diet and disease (Currey and Butler, 1975; Binford \& Bertram, 1977; Currey, 1979; Galloway et al., 1997; Willey et al., 1997; Chanesta et al., 2000; Munson, 2000; Symmons, 2002; Munson \& Garniewicz, 2003; Carlson \& Pickering, 2004; Lam \& Pearson, 2005). In addition, considerable disagreement exists, concerning the most valid method to calculate bone density (Lam \& Pearson, 2004; Outram, 2004: 172, Stiner, Q2 2004). Therefore, its potential for understanding variation in weathering is limited.

Element morphology also dictates decay rates (Henderson, 1987: 44). Tubular elements such as long bones are more susceptible to weathering with compact elements (e.g. carpals) less severely affected (Behrensmeyer, 1978: 152; von Endt and Ortner, 1984; Lambert et al., 1985; Potts, 1986; GiffordGonzales, 1989: 191; Nicholson, 1996: 527; Conard et al., 2008: 240). Elements with long, flat sections of cortex such as the mandible, pelvis and scapula have also been described as susceptible (Potts, 1986). Although clear patterns have been noted in the weathering of different elements, research has rarely identified taxon differences.

Previous research on weathering has tended to follow two pathways, either experimental research, observing signatures on modern bone, or scientific studies, aiming to explain the way that structural properties affect modification. Most research has been conducted on modern material and therefore may not be directly applicable to archaeological assemblages. In addition, research has at times provided conflicting or ambiguous results, and consequently it remains unclear which variables are most important in mediating weathering and which classes of remains are most likely to be modified.

Survival biases inevitably have a substantial effect on weathering prevalence. This is the case, as weathering is a degrading process that occurs during subaerial exposure when remains are also vulnerable to other taphonomic agents. Therefore, if identifiable remains exhibit weathering evidence, they must be robust enough to survive the effects of sustained subaerial exposure. This phenomenon may be termed the taphonomic paradox, whereby it is the robust fragments that survive degrading processes that in fact exhibit the greatest evidence of modification. This pattern is comparable with the osteological paradox that is commonly cited in human osteoarchaeology (see Wood et al., 1992). This states that skeletons that exhibit the greatest pathology are in fact from healthier or stronger individuals because they were able to survive long enough for the disease to manifest itself skeletally. However, this is not to say that weathering patterns result solely from survival bias because remains cannot be so resistant to modification that observable weathering evidence infrequently occurs. Weathering signatures in the archaeological record (rather than those in controlled experiments) must therefore result from interplay between susceptibility to modification and resistance to destruction. This research aims to characterise how this interplay manifests itself in weathering prevalence in British zooarchaeological assemblages.

Identifying which taxa and elements are most likely to be weathered provides a baseline from which to interpret modification patterns. This is the case as assemblages that are dominated by the classes of remains that invariably exhibit more weathering are highly likely to be heavily modified, and therefore signatures must be interpreted in light of this. It is crucial that this study deals with archaeological material because modification patterns in the archaeological record, which require interpretation and actualistic studies, although very useful in determining susceptibility, frequently omit a consideration of survival bias.

\section{Materials and methods}

\section{Data collection}

The analysed data set comprised 18,113 identifiable specimens derived from 10 sites from the UK (Figure 1, F1 Table 1). The weathering rate is relatively slow in tem-T1 perate climates and therefore analysis-targeted sites with surface accumulating deposits because these are likely to be more weathered and therefore provide a viable data set for investigating variation. The data set comprised a substantial quantity of material from later prehistoric middens because this research forms part of a wider study on taphonomy, in which middens were a case study. However, although more detailed analysis revealed some evidence for structured practice at certain sites (Madgwick, 2011), this was not nearly substantial enough to affect the overall data set. In any case, this was negated by the inclusion of a broad range of other assemblages from later prehistoric sites in the UK. The chronological, geographical, compositional and contextual diversity of the sample means that any culturally constituted modes of treatment at 


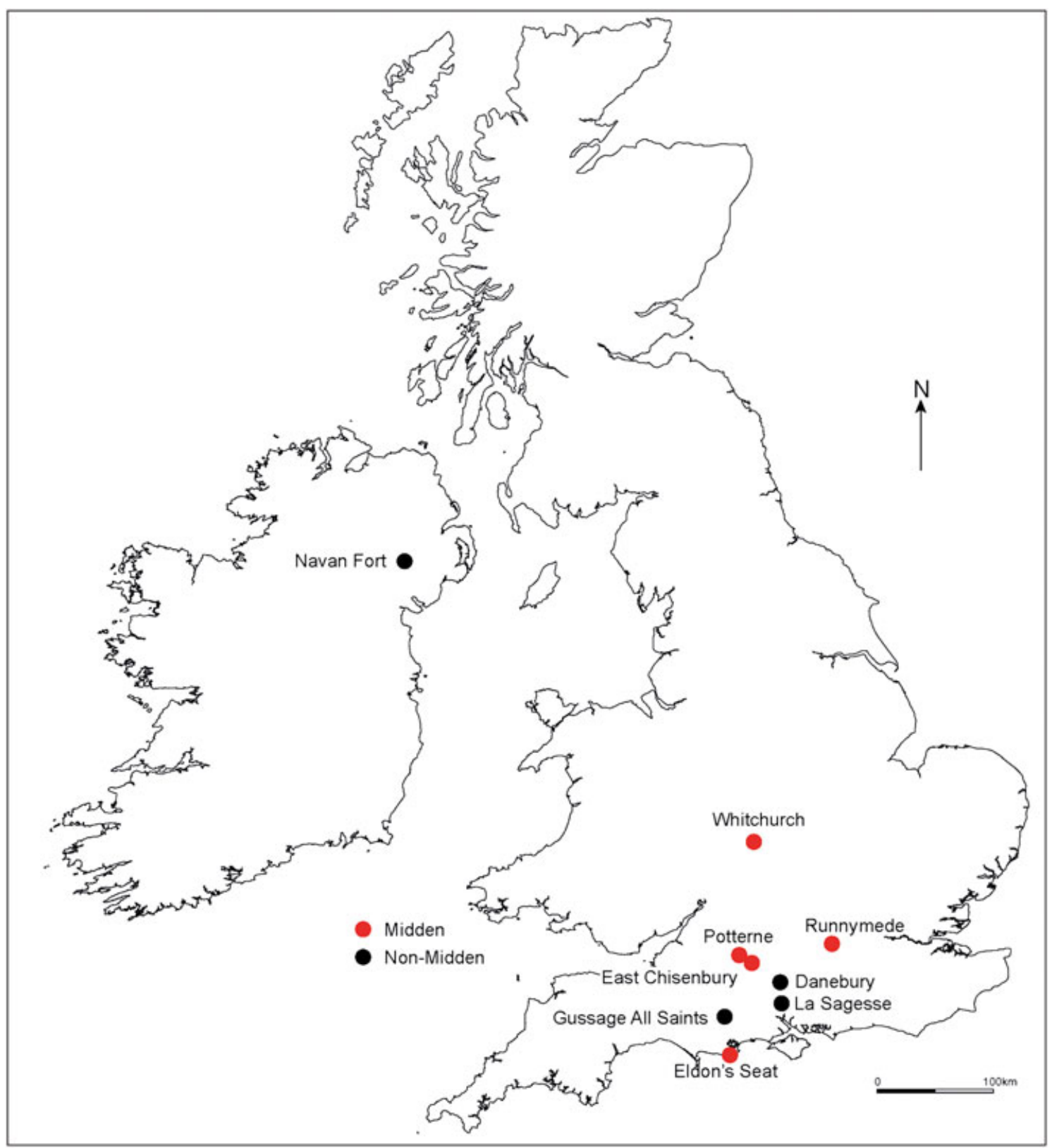

Figure 1. Map of the UK showing the locations of the 10 sites incorporated in the data set. This figure is available in colour online at wileyonlinelibrary. com/journal/oa.

an intrasite level would be absorbed. Therefore, the findings characterise variation in weathering in a British setting.

Weathering was recorded using Behrensmeyer's (1978) staged method (Table 2, Figures 2-4). This was considered a valid technique for recording modification on British material, and although experimentally determined in Africa, research has demonstrated that weathering is a progressive and irreversible process that follows a linear pathway regardless of environmental conditions (Tappen \& Peske, 1970; Behrensmeyer, 1978; Andrews, 1995: 149).

Analysis-targeted variables pertaining to class of material and archaeological context that may affect weathering. These comprise taxon, element, fusion stage, site and deposit type. Site is unlikely to provide indications of inherent effects on weathering pertaining to sedimentary matrices, hydrology or duration of burial because previous research indicates that the modification characteristic of subaerial rather than chemical 
Table 1. Details of the assemblages included in analysis

\begin{tabular}{|c|c|c|c|c|}
\hline Site & Phase & NISP & Site type & Whole/sample \\
\hline Danebury & Iron Age & 1620 & Hillfort & Sample \\
\hline East Chisenbury & Late Bronze Age/Early Iron Age & 534 & Midden & Whole \\
\hline Eldon's Seat & Late Bronze Age//ron Age & 1566 & Midden & Sample \\
\hline Gussage-all-Saints & Iron Age & 743 & Settlement & Sample \\
\hline La Sagesse & Iron Age/Medieval & 1102 & Stream deposits & Whole \\
\hline Llanmaes Enclosure & Iron Age/Romano-British & 395 & Settlement & Whole \\
\hline Navan Fort & Iron Age & 1944 & Hilltop enclosure & Whole \\
\hline Potterne & Late Bronze Age/Early Iron Age & 5903 & Midden & Sample \\
\hline Runnymede & Late Bronze Age/Early Iron Age & 1435 & Midden & Sample \\
\hline Whitchurch & Late Bronze Age/Iron Age & 2891 & Midden & Whole \\
\hline
\end{tabular}

The right-hand column indicates whether the whole assemblage or only a sample was analysed.

weathering rarely occurs in subterranean contexts. Instead it provides an index for the effect of site-specific depositional practice and disturbance and can be used to indicate the relative importance of human action and structural properties of remains in dictating weathering. Deposit type is included to indicate the effects of the characteristics of different deposits and the degree to which this mediates weathering signatures. For example, surface deposits such as occupation layers might

Table 2. Behrensmeyer's (1978) weathering stages for medium or large mammals $(>5 \mathrm{~kg})$

Stage 0: Bone surface shows no sign of cracking or flaking due to weathering.

Stage 1: Bone shows cracking, normally parallel to the fibre structure (e.g. longitudinal in long bones). Articular surfaces may show mosaic cracking.

Stage 2: Outermost concentric thin layers of bone show flaking, usually associated with cracks, in that the bone edges along the cracks tend to separate and flake first. Long thin flakes, with one or more sides still attached to the bone, are common in the initial part of this stage. Deeper and more extensive flaking follows until the outermost bone is gone. Crack edges are usually angular in cross section.

Stage 3: Bone structure is characterized by patches of rough, homogeneously weathered compact bone resulting in a fibrous texture. In these patches, all the external, concentric layers of bone have been removed. Gradually, the patches extend to cover the entire bone surface. Weathering does not penetrate deeper than $1.0-1.5 \mathrm{~mm}$ at this stage, and bone fibres are still firmly attached to each other. Crack edges are usually rounded in cross section.

Stage 4: The bone surface is coarsely fibrous and rough in texture; large and small splinters occur and may be loose enough to fall away from the bone if it is moved. Weathering penetrates into inner cavities. Cracks are open and have splintered or rounded edges.

Stage 5: Bone is falling apart, with large splinters. Bone is easily broken by moving. Original bone shape may be difficult to determine. Cancellous bone is usually exposed when present and may outlast all traces of the former more compact, outer parts of bone.

Stages 1 to 3 are presented in Figures $2-4$. be expected to exhibit more weathering than material from deep features such as pits. Sex could not be tested because the variable could be determined for comparatively few specimens. Depth could not be assessed in the same way because inevitably some contexts were very thick and incorporated a broad range of depths. Therefore, a separate pilot study at a single site that was excavated in arbitrary $10-\mathrm{cm}$ spits was undertaken but not reported here.

\section{Statistical analysis}

All statistical testing was undertaken using SPSS version 16 (SPSS Inc., Chicago, IL). The principal aim of analysis was to investigate the patterns of modification pertaining to elements and taxa. Initially simplified categories were used on the basis of morphology such as long bones, cranial elements and carpals, tarsals or phalanges. Certain taxa were also combined into single categories, such as wild boar and pig as suid and sheep and goat as caprine. These are called simplified categories. However, to maintain analytical rigour, tests were repeated using separate categories because bone density research indicates that morphology is not necessarily a valid means by which to group categories. These are called complex categories. Proximal fusion was used as the skeletal development-related variable because a greater number of specimens retained evidence of proximal, rather than distal, fusion.

\section{Classification trees}

The first phase of analysis used classification trees to identify variables, which had the greatest association with weathering. This procedure creates a tree-based classification model, classifying the different categories of independent variables (e.g. taxon, element, site, etc.) that affect a dependent variable (weathering). The procedure provides a method to rank independent variables in the order of the degree to which they explain 


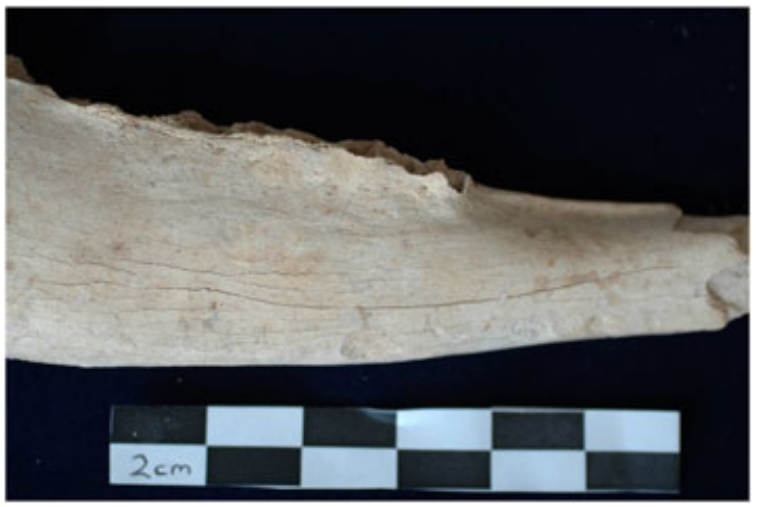

Figure 2. Example of stage 1 weathering on a cattle mandible. Note the split line cracks that follow the shape of the element (and the direction of collagen fibres). This figure is available in colour online at wileyonlinelibrary.com/journal/oa.

variance in weathering. Classification trees always have a single first level 'parent' variable that explains the greatest variance in the dependent. Independent variable categories that show similar relationships to the dependent variable are grouped into nodes. A very simple example tree testing an unidentifiable long bone

F5 fragment assemblage is presented in Figure 5. In this tree, site occupies the first level, with taxon category accounting for the second level branch and deposit type for the third level branches. This therefore demonstrates that site is most important in mediating modification, followed by taxon category and deposit type. In the example tree, only one level 2 and two level 3 branches are present. However, invariably many branches will be present, and the independent variable that occupies the greatest number of level 2

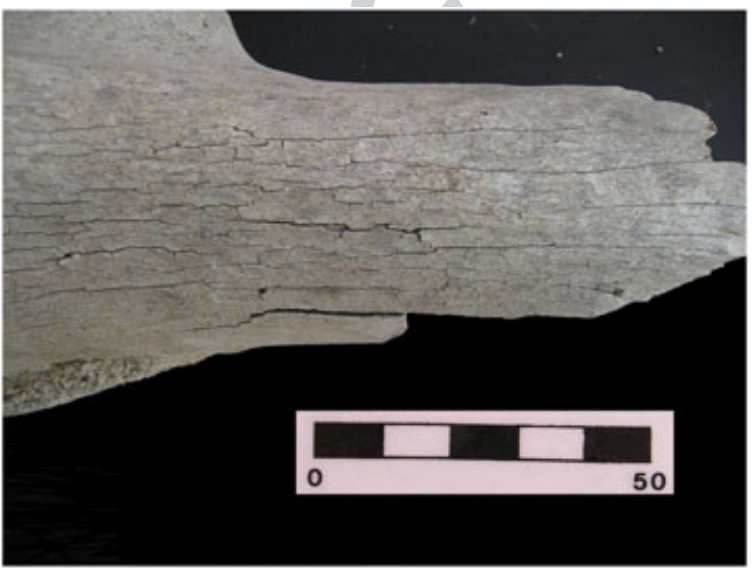

Figure 3. Example of early stage 2 weathering on an aurochs femur. Note that the split line cracks have begun to unite to become flakes. This figure is available in colour online at wileyonlinelibrary.com/journal/oa. branches is defined as having the next greatest effect after the level 1 parent branch. If two independent variables occupy the same number of level 2 branches, then the one that accounts for the most level 3 branches is defined as most important. Variables that do not appear in the tree have little or no effect on the dependent variable, and those that occupy only level 3 branches have a limited effect. A more comprehensive description of the approach is provided by Kinnear and Gray (2009). The CHAID growing method was used in analysis, and therefore trees had a maximum of three levels. To ensure that patterns identified in the tree pertained to substantial components of the data set, a minimum number of cases was set at 400 for parent nodes and 200 for child nodes.

\section{Regression models}

The second phase of analysis used ordinal regression to deduce which variable categories (e.g. radius, cattle, midden layer, etc.) are most likely to exhibit weathering evidence. All categories of all variables were analysed together as independent factors. Regression modelling provides a robust tool for assessing the effect of variable categories because the associated effects of all other categories are controlled in analysis. This is crucial as each specimen contributes to the patterns of several variables because it has a known taxon, element, deposit type and site. Regression models identify categories that have a significant effect (sig. $<0.05$ ) on modification prevalence when modelling the data set. As low weathering scores were most common, the negative log-log link method was used.

Conducting tests on a large and varied data set is critical for valid interpretation and reduces the likelihood of findings resulting from sampling bias. However, this also creates problems in interpretation. Incorporating in excess of 18,000 cases into analysis provides a highly statistically powerful data set, and consequently little variation from the expected patterns of modification is required for significant results in be obtained. Therefore, modelling the entire data set is certain to provide more significant results than are meaningful. Consequently, a modified bootstrapping approach was used (Efron, 1982), whereby each regression model was retested using reducing random samples until the model breaks down. Tests were conducted on the entire data set and on random samples of 10,000,5000, 2500, 1250, 625, 312 and 156 cases. Producing such a range of regressions is necessary to provide nuanced interpretation when testing a substantial data set. Significant results for variable 


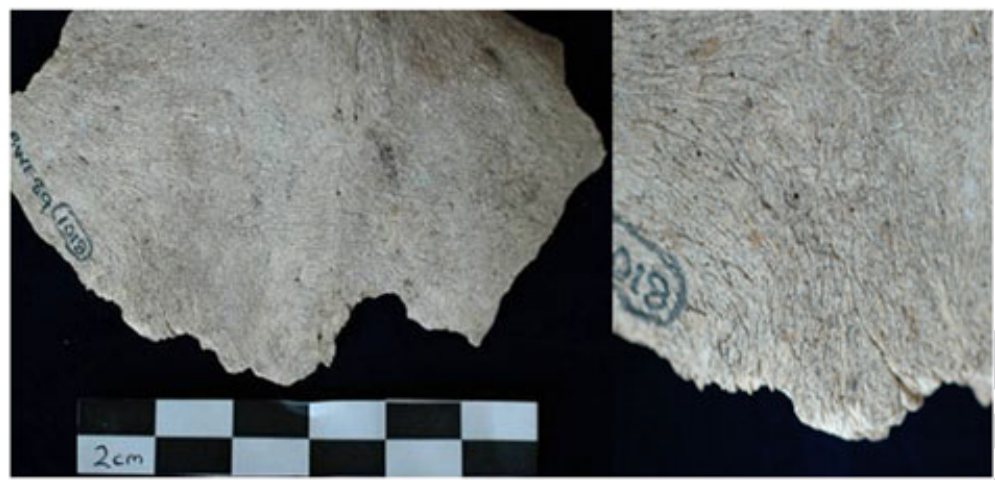

Figure 4. Example of stage 3 weathering on a cattle frontal. Note homogeneous, coarse texture on magnified inset. This figure is available in colour online at wileyonlinelibrary.com/journal/oa.

categories were totalled, providing a system by which to rank categories in terms of the degree to which they affect weathering in models. Results with negative coefficients indicated that the category reduced modification in the model, whereas positive coefficients demonstrated that it increased weathering.

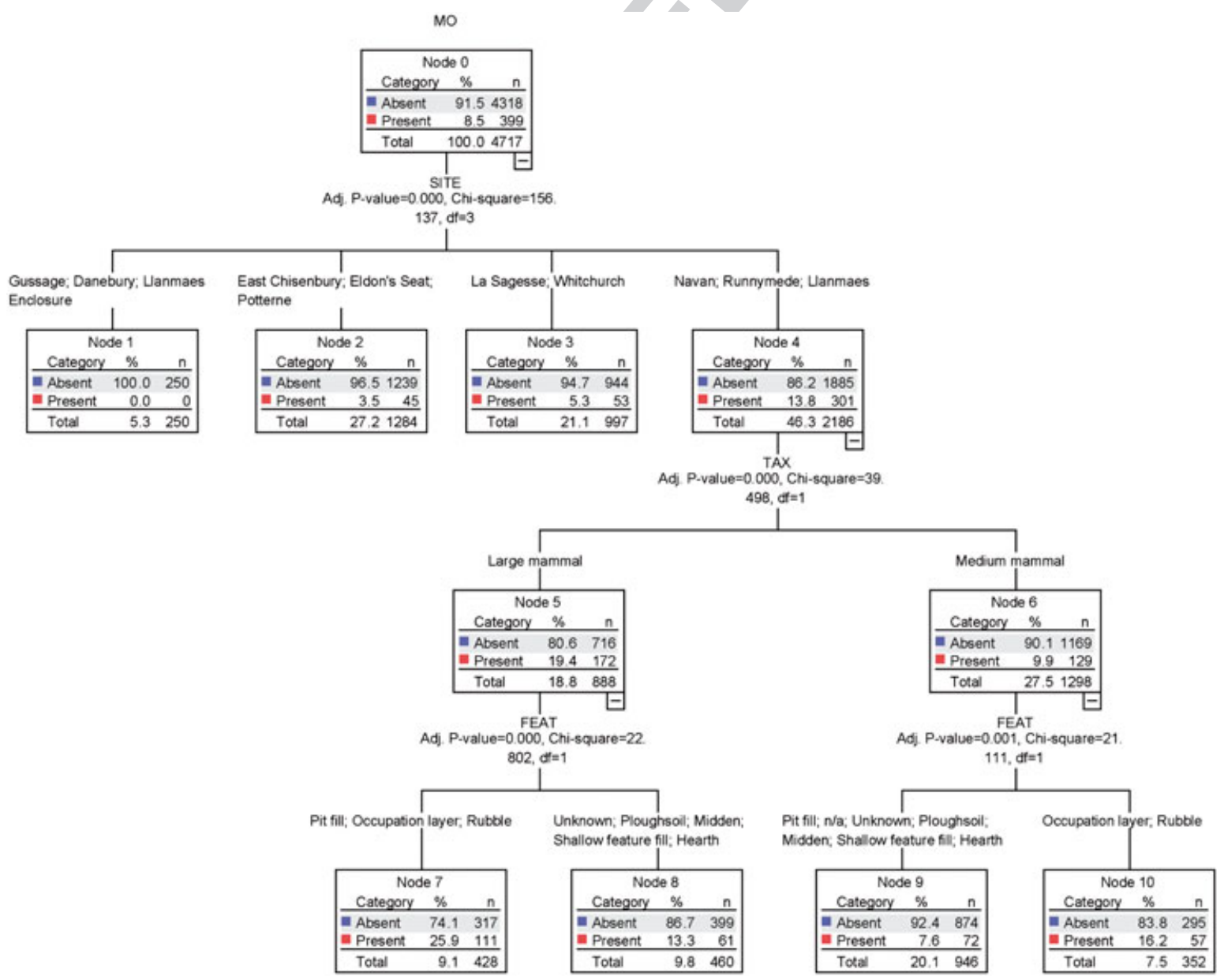

Figure 5. Example of a very simple classification tree taken from SPSS output. This figure is available in colour online at wileyonlinelibrary.com/ journal/oa. 


\section{Results}

\section{Classification trees}

Analysis provided unequivocal evidence of variables, which explain the greatest variance in weathering. Branch representation for the different variables is sum-

F6 marised in Figure 6. Using simplified and complex categories provided very similar results. Element occupied the level 1 branch in both trees and therefore was identified as the pivotal variable in mediating the weathering of those included in analysis. Site is clearly the next most important factor because it dominated level 2 branches, accounting for 7 of a total of 10 . The other three were occupied by taxon, which explained the next greatest variance in modification. Variables which occupy level 3 branches alone only have a significant effect in very specific circumstances. Therefore, fusion, which accounted for a single level 3 branch, had a far lesser effect, and because deposit type was absent from both trees, the effect of this variable on weathering must be negligible.

\section{Regression models}

Two regression series were produced, one using simplified variable categories and the other complex categories. Each comprised eight models that were computed for sequentially reducing random samples. Patterns are in broad accordance with classification tree results, with element and site categories producing the most significant results in both series. All categories that produced at least two significant results in the simplified

F7 category regression series are presented in Figure 7. Runnymede, Danebury and neonatal or juvenile had the greatest effect, each with five negative significant

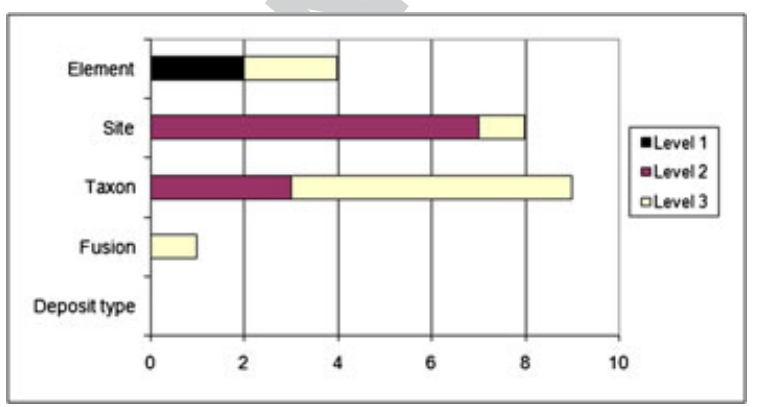

Figure 6. Summaries of branch representation in the two classification trees assessing which factors explain the greatest variance in weathering. Level 1 branches will always outrank level 2 branches, which in turn always outrank level 3 branches, regardless of the quantity of lower ranked branches. This figure is available in colour online at wileyonlinelibrary.com/journal/oa. results. Therefore, all reduced weathering in the model. Few positive results were produced, with mandible and horse having the greatest influence with three significant results each. This demonstrates that these classes of remains tend to be most frequently weathered. The categories of unfused subadult, small elements and East Chisenbury produced three negative significant results in the series. Therefore, these categories had reduced levels of weathering. Patterns were similar when incorporating all categories (Figure 8). The site of F8 Runnymede had the greatest effect, producing five significant results reducing weathering. Danebury accounted for four negative significant results, with horse, wild boar and mandible accounting for four positive. Categories that increased weathering in the model were more common than those in the simplified series. The five different long bone elements and the category of premaxilla produced three positive results.

\section{Discussion}

Classification tree analysis provided clear evidence that anatomical element explained the greatest variance in weathering in models. Site was the next most important in mediating modification followed by taxon. Fusion was also present in one tree but had only a negligible effect. As it is inconceivable that similar prescribed modes of treatment transcend the different sites in the data set, results indicate that the varying structural properties of elements and to a lesser extent taxa have a substantial effect on the prevalence and severity of weathering. This provides firm evidence that certain elements and taxa must be inherently more or less likely to be affected by weathering in archaeological assemblages. Therefore, weathering evidence cannot be interpreted at face value and does not simply reflect exposure duration.

The effect of site demonstrates the effect of variation in depositional practice and taphonomic trajectories. Because of the relatively broad range of analysed sites in terms of chronology, location and type, it was expected that site would explain the greatest variance in modification. As previous research clearly demonstrates that climate and environment are pivotal in controlling weathering, site would undoubtedly have had the greatest influence if this study included assemblages from more diverse settings. However, if climate and environment are similar, results suggest that anatomical element can be the most important factor in dictating the prevalence and severity of weathering. This is clearly the case within the data set, and because a sample of 10 sites would be expected to show 


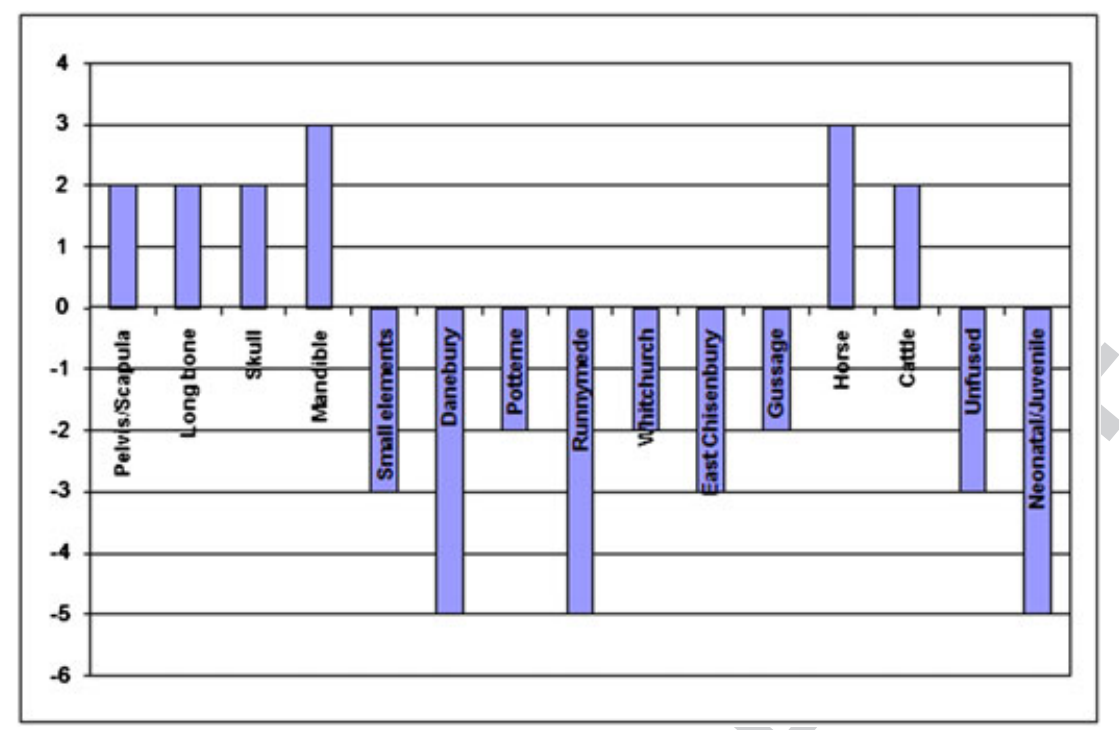

Figure 7. Graph showing the number of significant results produced for each variable category in regression models using simplified taxon and element categories. Categories that produced fewer than two significant results are not presented. This figure is available in colour online at wileyonlinelibrary. $\mathrm{com} /$ journal/oa.

considerable variation in depositional histories, the dominant effect of element must not be understated. Findings from classification trees demonstrate the importance of the regression analysis for establishing which classes of remains are inherently more or less likely to be modified. It is only with this information that taphonomic signatures can be validly assessed because assemblage composition has a significant bearing on modification.

Despite classification tree results, no element categories dominated in either series of regression models.
However, Figures 7 and 8 demonstrate that element produced many significant results, but they were divided between several categories. Overall sites produced fewer significant results than elements, but individual site categories had the greatest effect in models. Significant results pertaining to sites provide evidence for the effect of varied depositional practice and taphonomic trajectories (e.g. later disturbance). If results from the two model series are combined, Runnymede produced 10 negative results, more than any other category. Therefore, this site had a dominant effect in

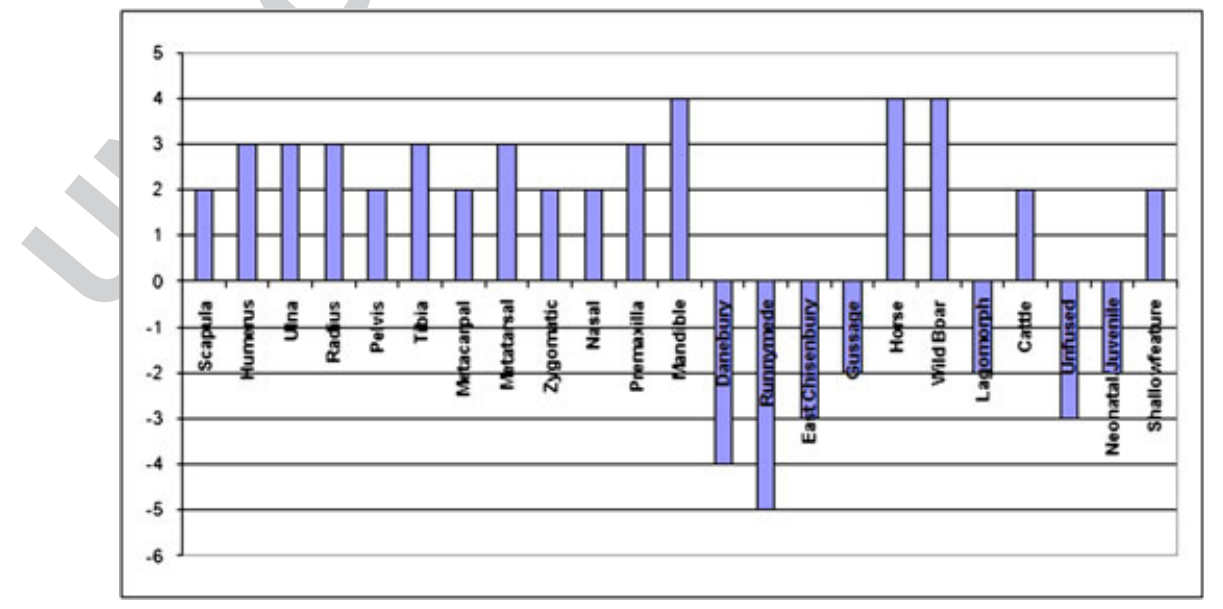

Figure 8. Graph showing the number of significant results produced for each variable category in regression models assessing taxon and element categories. Categories that produced fewer than two significant results are not presented. This figure is available in colour online at wileyonlinelibrary. $\mathrm{com} /$ journal/oa. 
reducing modification. The effect of Danebury was almost as strong, and East Chisenbury also made a noteworthy contribution, both reducing weathering. It was expected that certain site categories would have a significant influence on the model because it was always likely that certain sites would stand out in terms of their taphonomic histories.

The fusion categories of neonatal or juvenile and unfused subadult also had a substantial effect in reducing weathering in both series. There can be little doubt that this results from survival bias and the taphonomic paradox rather than susceptibility. Research has clearly demonstrated that undeveloped bones are less dense and therefore susceptible to destruction. Consequently, if bones are exposed on the surface long enough for weathering to occur, the fragile bones of neonatal, juvenile and subadult individuals are likely to degrade to a degree that they are not recovered or at least fusion evidence does not survive. This is an unavoidable feature of this mode of analysis because an age category can only be assigned when fusion evidence is observable, yet for evidence to be present, it is highly likely that remains were subject to rapid burial and therefore inherently less likely to show modification. Consequently, this approach has limited potential for assessing the relationship between weathering and skeletal development in faunal assemblages because the use of fusion as an index for development is fraught with difficulties. Therefore, interpretation is confined to the relatively obvious finding that the bones of immature individuals that retain fusion evidence are highly unlikely to exhibit weathering in the archaeological record.

Taxon categories were also prominent in both models. Horse had the strongest effect, accounting for seven positive significant results in the two series. Cattle had a lesser but still notable effect, and in the complex category series wild boar also made a substantial contribution in models. These categories all produced positive results, and consequently findings indicate that large mammal specimens are more likely to be affected by weathering. Large mammals generally have denser elements and have been frequently cited as more resistant to destruction and degrading processes (Behrensmeyer, 1978: 160; Behrensmeyer et al., 1979: 12; Gifford, 1981; Lyman, 1994; Ioannidou, 2003). However, results suggest that they may not be more resistant to weathering. This pattern is likely to partially relate to survival bias because these taxa are likely to survive during subaerial exposure to a degree where they remain identifiable. However, previous research assessing interelement variation in weathering has demonstrated that larger elements such as long bones and mandibulae, which are frequently denser, are genuinely more susceptible to weathering. This may therefore also be the case for large mammal specimens, and findings are interpreted as resulting from interplay of inherent susceptibility to modification and resistance to destruction. Establishing the degree to which each of these factors explains findings is beyond the remit of this study.

Only a single deposit category, shallow feature fill, produced as many as two significant results in either series. This relatively minor effect has limited interpretative potential but may be accounted for either the exposed bones being more frequently incorporated in shallow features or the occurrence of shallow subterranean weathering. The former seems a more likely interpretation, as previous research suggests subterranean weathering rarely occurs.

Results provide clear indications of factors affecting modification. However, certain unavoidable analytical biases must be recognised. Some variables were recorded for all specimens (e.g. site, element, taxon), whereas others could only be recorded for relatively well-preserved remains (e.g. fusion). Therefore, those which were recorded for all fragments had inherently greater statistical power and were more likely to produce significant results. However, this does little to diminish the validity of findings because sample size bias would have the greatest adverse effect on determining the effect of skeletal development. As discussed earlier, this exploratory approach has limited potential for investigating this variable in any case.

Characterising variation in weathering by identifying elements and taxa that are most frequently affected in British assemblages is vital to provide a baseline from which a more valid interpretation of weathering signatures can be made. This is the case, as an assessment of assemblage composition is crucial to understanding weathering patterns. Regression modelling demonstrated that mandibulae, long bones and premaxillae were more likely to exhibit weathering, and small elements (carpals, tarsals and phalanges) were infrequently affected. Further controlled experiments are required, but evidence from previous studies indicates that this is likely to result from genuine susceptibility or resistance to the modification rather than survival bias. Therefore, an assemblage dominated by susceptible specimens would be expected to exhibit greater evidence of weathering than one comprising a substantial proportion of resistant specimens. Consequently, variation in modification need not necessarily mean that the two assemblages underwent very different taphonomic trajectories because compositional differences can account for weathering patterns. If signatures 
contrast with expected patterns, then interpretations can be made about human action in depositional practice. For example, a deposit dominated by long bones that exhibits very little weathering must have been formed and protected in a subterranean environment very rapidly, whereas an assemblage in which small elements are heavily modified must have undergone substantial subaerial exposure.

Results showing that large mammals more frequently exhibit weathering evidence are likely to relate to interplay between survival bias and susceptibility. As survival bias is an important factor, the study of weathering evidence has a crucial role to play in ascertaining the degree to which subaerial exposure has affected taxon representation. For example, if large mammal elements dominate an assemblage and weathering evidence is scarce, taxon representation is unlikely to have been radically altered through subaerial exposure. By contrast if large mammals dominate an assemblage and weathering evidence is prevalent, it can be inferred that the representation of medium-sized mammals has been reduced through subaerial taphonomic processes. The effect of other taphonomic processes such as subterranean decay must of course also be considered.

An assessment of weathering evidence informed by findings in this study can also be used to investigate structured practices pertaining to the different classes of remains. The prescribed modes of predepositional treatment may have been common in past societies. The concept of 'ritual rubbish' is well attested to for British prehistory, and daily life is certain to have been heavily structured by rituals and codes of practice throughout the human past (see Hill, 1995; Madgwick, 2008, 2010; Randall, 2010). Weathering evidence combined with a consideration of assemblage composition provides a vital tool for ascertaining structuring principles in depositional practice concerning faunal remains. This research has characterised the expected patterns of the weathering of elements and taxa in a UK context. Therefore, if signatures in an assemblage do not conform to those identified in this research, prescribed practices pertaining to taxa or body parts may be inferred. For example, if weathering is prevalent in caprine remains within an assemblage yet scarce in cattle specimens, signatures contrast to the expected patterns defined in this study. Therefore, it can be inferred that the treatment of skeletal material was regulated according to taxon, with cattle remains subject to more rapid burial. However, for this interpretation to be made, the anatomical composition of the taxon-specific assemblages must be assessed because reduced weathering in cattle remains may result from a dominance of small elements, which are resistant to modification. This typifies the way in which findings from this study facilitate more rigorous approaches to the use of weathering data.

\section{Conclusion}

Weathering is unquestionably a highly complex process, and its rate, prevalence and severity is affected by wide-ranging variables. This study represents a new approach using multivariate statistical techniques to gain a greater understanding of variation in weathering in archaeological deposits and complements previous actualistic experimental studies. Results provide new insights into the nature of weathering and the factors dictating its prevalence, but considerable further research is required. It must be emphasised that findings pertain only to British material and further studies on a broader range of sites with a wider variety of fauna have the potential to substantially enhance the understanding of the weathering process. Although the data set tested in this research is relatively large, it comprises data from only 10 assemblages, and it would be greatly beneficial for the research to be repeated in the future on further British data sets to test the reliability of findings.

With an increased understanding of variation in modification, the interpretative potential of weathering data is enhanced and its applications widened. On the basis of the findings from this research, more rigorous approaches can be developed to determine differences in taphonomic trajectories between deposits or assemblages and to establish the degree to which subaerial exposure has skewed species representation. In addition, weathering data can be applied to identify culturally constituted modes of depositional practice. Combined with results from experimental studies, findings from this research facilitate a more valid interpretation of weathering patterns and provide a further tool for untangling issues of equifinality in zooarchaeological assemblages.

\section{Acknowledgements}

The authors are very grateful to Amanda Robinson, Jonathan Gillard, Colin Davies and Paul McGeoghan for guidance with statistical approaches and two anonymous reviewers for insightful comments on an earlier version of this article. The authors also thank Ian Dennis for assistance with image formatting and the following people who assisted with access to material 
in museums: Lisa Webb, David Dawson, David Allen, Kay Ainsworth, Alan Jacobs, Peter Woodward, Ben Roberts, Marianne Eve, Debbie Buck, Adam Gwilt, Jodie Deacon, Finbar McCormick and Malcolm Fry. This project was funded by the Arts and Humanities Research Council.

\section{References}

Andrews P. 1995. Experiments in taphonomy. Journal of Archaeological Science 22: 147-153.

Bar-Oz G and Munro ND. 2004. Beyond cautionary tales: A multivariate taphonomic approach for resolving equifinality in zooarchaeological studies. Journal of Taphonomy 2 : 201-220.

Behrensmeyer AK. 1978. Taphonomic and ecological information from bone weathering. Paleobiology 4: 150-162.

Behrensmmeyer AK, Kidwell SM and Gastaldo RA. 2000. Taphonomy and paleobiology. Paleobiology 26: 103-147.

Behrensmeyer AK, Webster D and Dechant Boaz DE. 1979. New perspectives in vertebrate palaeoecology from a recent bone assemblage. Paleobiology 5: 15-21.

Binford LR and Bertram JB. 1977. Bone frequencies and additional processes. In For Theory Building in Archaeology. LR Binford. (ed.). Academic Press: New York; 77-153.

Boaz DD. 1982. Modern Riverine Taphonomy: Its Relevance to the Interpretation of Plio-Pleistocene Hominid Palaeoecology in the Omo Basin, Ethiopia. University Microfilms, Ann Arbor: Michigan.

Butler VL and Chatters JC. 1994. The role of bone density in structuring prehistoric salmon bone assemblages. Journal of Archaeological Science 21: 413-424.

Carlson KJ and Pickering TR. 2004. Shape-adjusted bone mineral density measurements in baboons: other factors explain primate skeletal element representation at Swartkrans. Journal of Archaeological Science 31: 577-583.

Chanesta F, Hillman L, Thomas M, Keisler D 2000. Estrogen agonist (Zeranol) treatment in castrated male lamb model: Effects on growth and bone mineral accretion. Journal of Bone and Mineral Research 15: 1361-1367.

Collins MJ, Nielsen-Marsh CM, Hiller J, Smith CI, Roberts JP, Wess TJ, Csapo TJ, Millard AR, Priyodich RV and Turner-Walker G. 2002. The survival of the organic matter of bone: A review. Archaeometry 44: 383-394.

Conard NJ, Walker SJ and Kandel AW. 2008. How heating and cooling and wetting and drying can destroy dense faunal elements and lead to differential preservation. Palaeogeograpby, Palaeoclimatology, Palaeoecology 266: 236-245.

Currey J. 1979. Changes in the impact energy absorption with age. Journal of Biomechanics 12: 459-469.

Currey, J and Butler G. 1975. The mechanical properties of bone tissue in children. Journal of Bone and Joint Surgery 57: 810-814.

Dirrigl FJ. 2001. Bone mineral density of wild turkey (Meleagris gallopavo) skeletal elements and its effect on differential survivorship. Journal of Archaeological Science 28: 817-832.
Efron B. 1982. The Jackknife, the Bootstrap, and other Resampling Plans. CBMS-NSF Monograph no. 38. Society of Industrial and Applied Mathematics: Bristol.

Elkin DC. 1995. Volume density of South American camelid skeletal parts. International Journal of Osteoarchaeology 5: 29-37.

Enloe JG. 2004. Equifinality, assemblage integrity and behavioral inferences at Verberie. Journal of Taphonomy 2: 147-165.

Fernández-Jalvo Y and Marín Monfort MD. 2008. Experimental taphonomy in museums: Preparation protocols for skeletons and fossil vertebrates under the scanning electron microscopy. Geobios 41: 157-181.

Fisher JW. 1995. Bone surface modifications in zooarchaeology. Journal of Arcbaeological Method and Theory 2: 7-68.

Frison GC and Todd LC. 1986. The Colby Mammotb Site: Taphonomy and Archaeology of a Clovis Kill in Northern Wyoming. University of New Mexico Press: Albuquerque.

Galloway A, Willey P and Snyder L. 1997. Human bone mineral densities and survival of bone elements: A contemporary sample. Forensic Taphonomy: The Post-Mortem Fate of Human Remains. WD Haglund and M Sorg (eds.). CDC Press: Boca Raton; 295-317.

Gifford DP. 1977. Observations of Modern Human Settlements as an Aid to Archaeological Interpretation. $\mathrm{PhD}$ Thesis, University of California, Berkeley. University Microfilms, Ann Arbor: Michigan.

Gifford DP. 1981. Taphonomy and palaeoecology: A critical review of archaeology's sister disciplines. In Advances in Archaeological Method and Theory Volume 4. MB Schiffer (ed.). Academic Press: New York; 365-438.

Gifford-Gonzales DP. 1989. Ethnographic analogues for interpreting modified bones; Some cases from East Africa. In Bone Modification. R Bonnischen and MH Sorg (eds.). Centre for the Study of the First Americans, Institute for Quaternary Studies, University of Maine: Orono, Maine 179-246.

Hedges REM. 2002. Bone diagenesis: An overview of processes. Archaeometry 44: 319-328.

Hedges REM and Millard AR. 1995. Measurements and relationships of diagenetic alteration of bone from three archaeological sites. Journal of Archaeological Science 22: 201-211.

Henderson J. 1987. Factors determining the state of preservation of human remains. In Death Decay and Reconstruction: Approaches to Archaeology and Forensic Science. A Boddington, AN Garland and RC Janaway (eds.). University of Manchester Press: Manchester; 43-54.

Hill JD. 1995. Ritual and Rubbish in the Iron Age of Wessex. BAR British Series 242. Tempus Reperatum: Oxford.

Ioannidou E. 2003. Taphonomy of animal bones: Species, sex, age and breed: Variability of sheep, cattle and pig bone density. Journal of Archaeological Science 30: 355-365.

Kinnear PR and Gray CD. 2009. SPSS 16 Made Simple. Psychology Press: New York.

Kooyman B. 2001. The roles of bone density and cultural behaviour in Head-Smashed-In bone bed taphonomy. In People and Wildlife in Northern North America: Essays in Honour of R. Dale Gutbrie. SC Gerlach and MS Murray 
(eds.). BAR International Series 944. Archaeopress: Oxford; 285-293.

Kreutzer A. 1992. Bison and deer bone mineral densities: Comparisons and implications for the interpretation of archaeological faunas. Journal of Archaeological Science 19: 271-294.

Lam YM, Chen X, Marean CW and Frey CJ. 1998. Bone density and long bone representation in archaeological faunas: Comparing results from CT and Photon densitometry. Journal of Archaeological Science 25: 559-570.

Lam YM, Chen X and Pearson OM. 1999. Intertaxonomic variability in patterns of bone density and the differential representation of bovid, cervid, and equid elements in the archaeological record. American Antiquity 64: 343-362.

Lam YM and Pearson OM. 2004. The fallibility of bone density values and their use in archaeological analyses. Journal of Taphonomy 2: 99-115.

Lam YM and Pearson OM. 2005. Bone density studies and the interpretation of the faunal record. Evolutionary Anthropology 14: 99-108

Lam YM, Pearson OM, Marean CW and Chen X. 2003. Bone density studies in zooarchaeology. Journal of Archaeological Science 30: 1701-1708.

Lambert JB, Simpson SV, Weiner JG and Buikstra JE. 1985. Induced metal-ion exchange in excavated human bone. Journal of Archaeological Science 12: 85-92.

Lyman RL. 1993. Density mediated attrition of bone assemblages: New insights. In From Bones to Behaviour. J Hudson (ed.). Center for Archaeological Investigations, Southern Illinois University: Carbondale; 324-341.

Lyman RL. 1994. Vertebrate Taphonomy. Cambridge University Press: Cambridge.

Lyman RL and Fox GL. 1989. A critical evaluation of bone weathering as an indication of bone assemblage formation. Journal of Archaeological Science 16:293-317.

Lyman RL, Houghton LE and Chambers AL. 1992. The effect of structural density on marmot skeletal part representation in archaeological sites. Journal of Archaeological Science 19: 557-573.

Maat GJR. 1993. Bone preservation, decay and its related condition in ancient human bones from Kuwait. International Journal of Osteoarchaeology 3: 77-86.

Madgwick R. 2008. Patterns in the modification of human and animal bones in Iron Age Wessex: Revisiting the excarnation debate. In Changing Perspectives on the First Millennium BC. O Davis, N Sharples and K Waddington (eds.). Oxbow: Oxford i 99-118.

Madgwick R. 2010. Bone modification and the conceptual relationship between humans and animals in Iron Age Wessex. In Integrating Social and Environmental Archaeologies: Reconsidering Deposition. J Morris and M Maltby (eds.). BAR International Series 2077. Archaeopress: Oxford; 66-82.

Madgwick R. 2011. Investigating the Potential of Holistic Taphonomic Analysis in Zooarchaeological Research. Unpublished PhD thesis, Cardiff University.

Millard AR and Hedges REM. 1995. The role of the environment in uranium uptake by buried bone. Journal of Archaeological Science 22: 239-250.
Munson PJ. 2000. Age-correlated differential destruction of bones and its effect on archaeological mortality profiles of domestic sheep and goats. Journal of Archaeological Science 27: 391-407.

Munson PJ and Garniewicz RC. 2003. Age-mediated survivorship of ungulate mandibles and teeth in canidravaged faunal assemblages. Journal of Archaeological Science 30: 405-416.

Murphy L, Barnett BG, Holloway RG and Sheldon CM. 1981. An experiment to determine the effects of wet/dry cycling on certain common cultural materials. In The Final Report of the National Reservoir Inundation Study. Vol. 2. DJ Lenihan, TL Carrell, S Fosberg, L Murphy, SL Rayl and JA Ware (eds.). Technical Report USDI, National Park Service, Southwest Cultural Resources Center: Sante Fe, Q3 8-i-8-43.

Nicholson RA. 1996. Bone degradation, burial medium and species representation: Debunking the myths, an experiment based approach. Journal of Archaeological Science 23: 513-533.

Outram AK. 2004. Applied models and indices versus high resolution observed data: Detailed fracture and fragmentation analyses for the investigations of skeletal part abundance patterns. Journal of Taphonomy 2: 167-184.

Pavao B and Stahl PW. 1999. Structural density Assays of leporid skeletal elements with implications for taphonomic, actualistic and archaeological research. Journal of Archaeological Science 26: 53-66.

Pinto Llona AC and Andrews PJ. 1999. Amphibian taphonomy and its application to the fossil record of Dolina (middle Pleistocene, Atapuerca, Spain). Palaeogeograpby, Palaeoclimatology, Palaeoecology 149: 411-429.

Potts R. 1984. Home bases and early hominids. American Scientist 72: 338-347.

Potts R. 1986. Temporal span of bone accumulations at Olduvai Gorge and implications for early hominid foraging behaviour. Palaeobiology 12: 25-31.

Purdy BA and Clark DE. 1987. Weathering of inorganic materials: Dating and other applications. In Advances in Archaeological Method and Theory Vol. 11. MB Schiffer (ed.). Academic Press: San Diego; 211-253.

Randall C. 2010. More ritual rubbish? Exploring the taphonomic history, context formation processes and 'specialness' of deposits including human and animal bone in Iron Age pits. In Integrating Social and Environmental Archaeologies: Reconsidering Deposition. J Morris and M Maltby (eds.). BAR International Series 2077. Archaeopress: Oxford 83-102.

Riclefs RE. 1973. Ecology. Chiron Press: Portland.

Ross AH. and Cunningham SL. 2011. Time-since-death and bone weathering in a tropical environment. Forensic Science International 204: 126-133.

Russell A. 2010. Structured deposition or casual disposal of human remains? A case study of four Iron Age sites from southern England. In Integrating Social and Environmental Archaeologies: Reconsidering Deposition. J Morris and M Maltby (eds.). BAR International Series 2077. Archaeopress: Oxford; $45-65$. 
Saunders JJ. 1977. Late Pleistocene vertebrates of the Western Ozark Higbland, Missouri. Illinois State Museum Reports of Investigations. No. 33. Illinois State Museum: Springfield.

Serjeantson D. 1991. Rid grasse of bones: A taphonomical study of the bones from midden deposits at the Neolithic and Bronze Age site at Runnymede, Surrey, England. International Journal of Osteoarchaeology 1 : 73-89.

Serjeantson D. 1996. The animal bones. In Runnymede Bridge Research Excavations, Volume 2 Refuse and Disposal at Area 16 East, Runnymede. S Needham and T Spence (eds.). British Museum Press: London; 194-223.

Smith CI, Faraldos M and Fernández-Jalvo Y. 2008. The precision of porosity measurements: Effects of sample pretreatment on porosity measurements of modern and archaeological bone. Palaeogeograpby, Palaeoclimatology, Palaeoecology 266: 175-182.

Steele, DG. and Carson DL. 1989. Excavation and taphonomy of mammoth remains from the Duewall-Newberry Site, Brazos County, Texas. In Bone Modification. R Bonnischen and MH Sorg (eds.). Centre for the Study of the First Americans, Institute for Quaternary Studies, University of Maine: Orono, Maine; 413-430.

Stiner MC. 2004. A comparison of photon densitometry and computed tomography parameters of bone density in ungulate body part profiles. Journal of Taphonomy 2: 117-145.

Symmons R. 2002. A Re-examination of Sheep Bone Density and its Role in Assessing Taphonomic Histories of Zooarchaeological Assemblages. Unpublished PhD thesis, University of London.

Symmons R. 2005a. New density data for unfused and fused sheep bones, and a preliminary discussion on the modelling of taphonomic bias in archaeofaunal age profiles. Journal of Archaeological Science 32: 1691-1698.

Symmons R. 2005b. Bone density variation between similar animals and density variation in early life: Implications for future taphonomic analysis. In Biosphere to Lithosphere: New Studies in Vertebrate Taphonomy. T O'Connor (ed.). 9th ICAZ Conference, Durham 2002. Oxbow: Oxford; 87-93.

Tappen M. 1994. Bone weathering in the tropical rainforest. Journal of Archaeological Science 21: 667-673.

Tappen NC and Peske GR. 1970. Weathering cracks and split line patterns in archaeological bone. American Antiquity 35: 383-386.

Todisco D and Monchot H. 2008. Bone weathering in a periglacial environment: The Tayara Site (KbFk-7), Qikirtaq Island, Nunavik (Canada). Artic 61:87-101.

Trueman CN, Behrensmeyer AK, Tuross N and Weiner S. 2004. Mineralogical and compositional changes in bone exposed on soil surfaces in Amboseli National Park, Kenya: Diagenetic mechanisms and the role of sedimentary pore fluids. Journal of Archaeological Science 31: 721-739.

von Endt DW. and Ortner DM. 1984. Experimental effects of bone size and temperature on bone diagenesis. Journal of Archaeological Science 11 : 247-253.

Willey P, Galloway A and Snyder L. 1997. Bone mineral density and survival of elements and element portions in the bones of the Crow Creek massacre victims. American Journal of Pbysical Antbropology 104: 513-528.

Wood JW, Milner GR, Harpending HC and Wiess KM. 1992. The osteological paradox. Problems of inferring prehistoric health from skeletal samples. Current Antbropology 33: 343-370. 


\section{Author Query Form}

\section{Journal: International Journal of Osteoarchaeology}

\section{Article: oa_1274}

Dear Author,

During the copyediting of your paper, the following queries arose. Please respond to these by annotating your proofs with the necessary changes/additions.

- If you intend to annotate your proof electronically, please refer to the E-annotation guidelines.

- If you intend to annotate your proof by means of hard-copy mark-up, please refer to the proof mark-up symbols guidelines. If manually writing corrections on your proof and returning it by fax, do not write too close to the edge of the paper. Please remember that illegible mark-ups may delay publication.

Whether you opt for hard-copy or electronic annotation of your proofs, we recommend that you provide additional clarification of answers to queries by entering your answers on the query sheet, in addition to the text mark-up.

\begin{tabular}{|c|c|c|}
\hline Query No. & Query & Remark \\
\hline Q1 & AUTHOR: Please define "NISP." & \\
\hline Q2 & $\begin{array}{l}\text { AUTHOR: The citation "Lam \& Pearson, 1994" (original) has been changed to "Lam } \\
\text { \& Pearson, 2004". Please check if appropriate. }\end{array}$ & \\
\hline Q3 & $\begin{array}{l}\text { AUTHOR: Please check captured publisher name, Publisher location and page range if } \\
\text { appropriate. }\end{array}$ & \\
\hline Q4 & AUTHOR: Please check publisher name if appropriate. & \\
\hline Q5 & AUTHOR: Please check captured publisher name if appropriate. & \\
\hline Q6 & AUTHOR: Please check captured book series title if appropriate. & \\
\hline
\end{tabular}




\section{USING E-ANNOTATION TOOLS FOR ELECTRONIC PROOF CORRECTION}

\section{Required Software}

Adobe Acrobat Professional or Acrobat Reader (version 7.0 or above) is required to e-annotate PDFs. Acrobat 8 Reader is a free download: http://www.adobe.com/products/acrobat/readstep2.html

Once you have Acrobat Reader 8 on your PC and open the proof, you will see the Commenting Toolbar (if it does not appear automatically go to Tools>Commenting>Commenting Toolbar). The Commenting Toolbar looks like this:

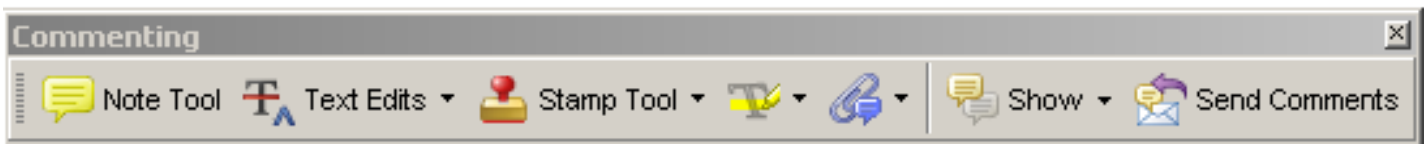

If you experience problems annotating files in Adobe Acrobat Reader 9 then you may need to change a preference setting in order to edit.

In the "Documents" category under "Edit - Preferences", please select the category 'Documents' and change the setting "PDF/A mode:" to "Never".

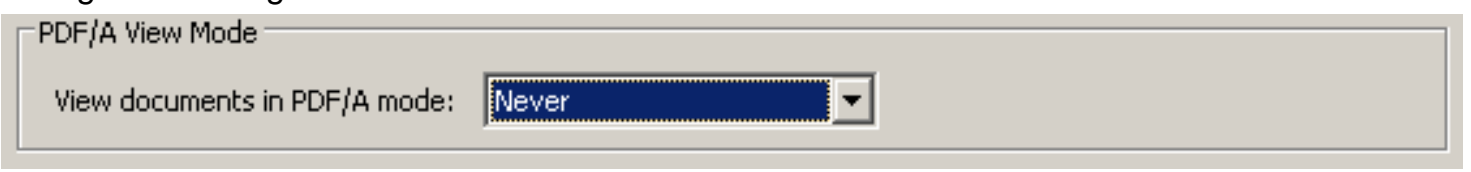

\section{Note Tool - For making notes at specific points in the text}

Marks a point on the paper where a note or question needs to be addressed.

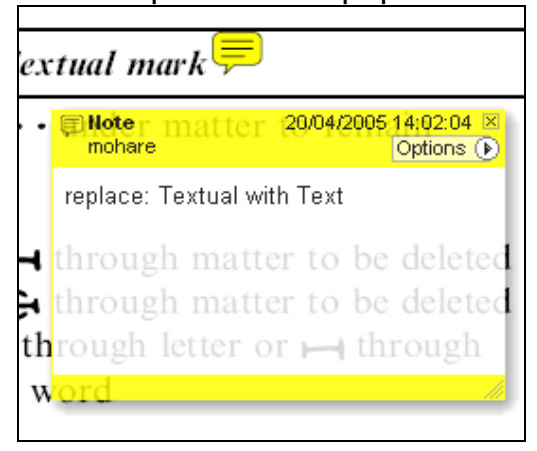

\section{How to use it:}

1. Right click into area of either inserted text or relevance to note

2. Select Add Note and a yellow speech bubble symbol and text box will appear

3. Type comment into the text box

4. Click the $X$ in the top right hand corner of the note box to close.

\section{Replacement text tool - For deleting one word/section of text and replacing it}

Strikes red line through text and opens up a replacement text box.

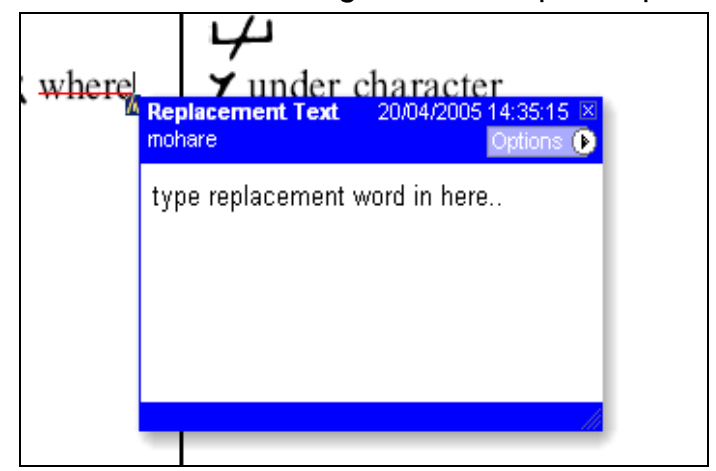
How to use it:
1. Select cursor from toolbar
2. Highlight word or sentence
3. Right click
4. Select Replace Text (Comment) option
5. Type replacement text in blue box
6. Click outside of the blue box to close

\section{Cross out text tool - For deleting text when there is nothing to replace selection}

Strikes through text in a red line.

\begin{tabular}{|l|}
\hline substitute part of one or \\
more word(s) \\
Change to italies \\
Change to capitals \\
Change to small capitals \\
\hline
\end{tabular}
How to use it:
1. Select cursor from toolbar
2. Highlight word or sentence
3. Right click
4. Select Cross Out Text 


\section{WILEY-BLACKWELL}

Approved tool - For approving a proof and that no corrections at all are required.

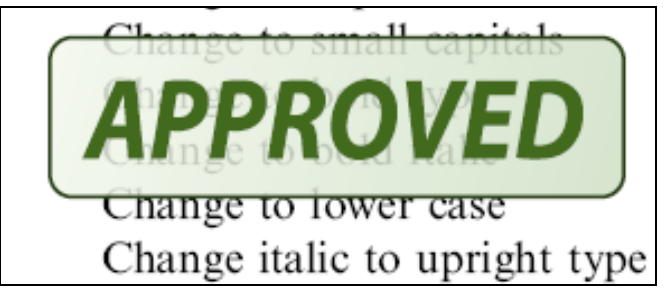

\section{How to use it:}

1. Click on the Stamp Tool in the toolbar

2. Select the Approved rubber stamp from the 'standard business' selection

3. Click on the text where you want to rubber stamp to appear (usually first page)

Highlight tool - For highlighting selection that should be changed to bold or italic. Highlights text in yellow and opens up a text box.

\begin{tabular}{|c|c|}
\hline & \\
\hline puble quotation & (As above) \\
\hline phen $\begin{array}{c}\text { Highlight } \\
\text { mohare }\end{array}$ & $\begin{array}{l}\text { 20:04:2005 14:45:47 } x \\
\text { Options (i) }\end{array}$ \\
\hline N par & \\
\hline parą & \\
\hline $\mathrm{se}$ & \\
\hline$p$ & \\
\hline ace b & \\
\hline
\end{tabular}

\section{How to use it:}

1. Select Highlighter Tool from the commenting toolbar

2. Highlight the desired text

3. Add a note detailing the required change

Attach File Tool - For inserting large amounts of text or replacement figures as a files. Inserts symbol and speech bubble where a file has been inserted.

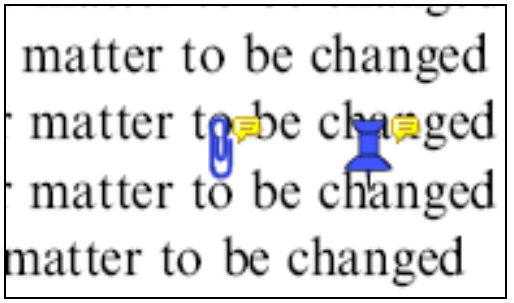

How to use it:

1. Click on paperclip icon in the commenting toolbar

2. Click where you want to insert the attachment

3. Select the saved file from your PC/network

4. Select appearance of icon (paperclip, graph, attachment or tag) and close

\section{Pencil tool - For circling parts of figures or making freeform marks}

Creates freeform shapes with a pencil tool. Particularly with graphics within the proof it may be useful to use the Drawing Markups toolbar. These tools allow you to draw circles, lines and comment on these marks.

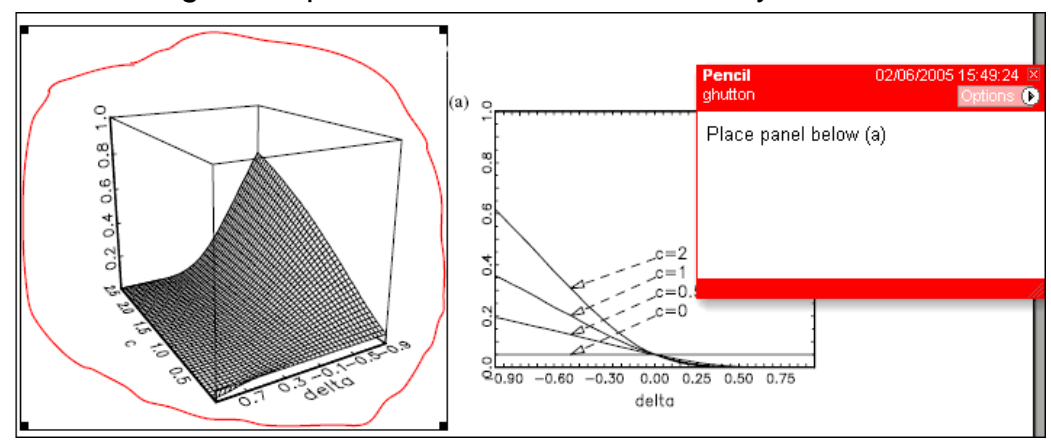

How to use it:

1. Select Tools $>$ Drawing Markups $>$ Pencil Tool

2. Draw with the cursor

3. Multiple pieces of pencil annotation can be grouped together

4. Once finished, move the cursor over the shape until an arrowhead appears and right click

5. Select Open Pop-Up Note and type in a details of required change

6. Click the $X$ in the top right hand corner of the note box to close. 
Help

For further information on how to annotate proofs click on the Help button to activate a list of instructions:

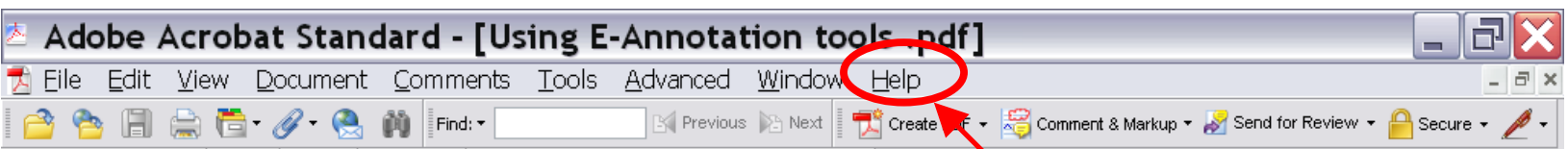

